Special Issue of the 8th International Advances in Applied Physics and Materials Science Congress (APMAS 2018)

\title{
Prediction of the Asphalt Mixture Performance Prepared with Recycled Fine Aggregate by using Response Surface Analysis
}

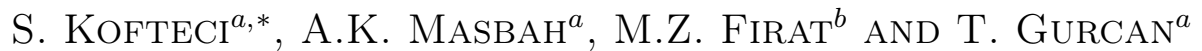 \\ ${ }^{a}$ Akdeniz University, Department of Civil Engineering, 07050 Antalya, Turkey \\ ${ }^{b}$ Akdeniz University, Department of Animal Science, 07050 Antalya, Turkey
}

\begin{abstract}
Applying new techniques such as numerical method would prepare more facilities to estimate the result of experimental studies.In this research, performance of asphalt mixtures prepared with recycled aggregates was measured by using response surface analysis method. For this aim, recycled aggregates obtained from chip seal roads were used as fine aggregates with new aggregates in asphalt mixtures. Recycled aggregates were added into the mixture with $25,50,75,100 \%$ ratios. $50 / 70$ and 70/100 penetration bitumens were used as binder in the prepared mixtures. In order to measure the perfromance of mixtures, Marshall stability, flow, cantabro were performed. The results obtained from response surface analysis showed that, the estimation models have $R^{2}$ values higher than 80. This means that, response surface analysis can be used as a numerical method for the prediction of asphalt mixture perfomance.
\end{abstract}

DOI: 10.12693/APhysPolA.135.900

PACS/topics: highway pavement, recycled aggregate, waste management, Marshall stability, response surface analysis

\section{Introduction}

Increasing economic cost and lack of availability of natural materials have opened the opportunity to explore the local available recycled materials. Aggregate that is used in asphalt mixture is usually obtained from natural resources, such as basalt, granite and limestone which are exploited and processed into crushed stone with various sizes and specific gradation. Furthermore, daily utilization of natural materials and demolishing of structures, roll up the lack availability of virgin materials problem. Therefore, it necessitates the recycling material and use them almost as a substitution of virgin material. In the recent years with the development of science and technology, investigators try to use new methods such as response surface analysis (RSA) in order to analyze data obtained from the different tests easily.

RSA is well-known as a beneficial statistical analysis in modeling curvature effects in many scientific areas [1]. The effect of different amount of additive on fatigue life of asphalt which calculated with response surface method shows that, the fatigue life of specimens increased when the level of test strains decreased [2]. Effect of compaction temperature, rediset contents and asphalt binder contents on the volumetric and strength properties of warm asphalt mix have been evaluated by response surface method and show that, optimum bitumen content (OBC) of warm mix asphalt compacted at high temperature is higher than $\mathrm{OBC}$ of warm mix asphalt compacted

*corresponding author; e-mail: skofteci@akdeniz.edu.tr at lower temperature [3]. The fracture toughness characteristics that affect the cracking performance of different asphalt mixtures can be calculated with response surface method and the result of this method show a good agreement with the expected data which confirm the appropriateness of the optimization process [4]. Response surface method has been conducted in the various investigations such as civil engineering [5-7], mechanical engineering $[8]$ geotechnical engineering $[9,10]$ to evaluate material performance without too many experiments. In this study after the conducting various tests such as Marshall stability, flow, cantabro, performace of mix asphalt that obtained from the certain percentage of recycled aggregate, virgin aggregates and two different types of bitumen $(70 / 100,50 / 70)$ were evaluated by using RSA method.

\section{Materials and equipments}

Marshall stability that is the identifier of specimens resistance to plastic deformation under the maximum load at rate of $5 \mathrm{~mm}$ per minute was conducted in order to evaluate the specimens stability until failure, maximum load that leads specimens failure is Marshall stability and variation of specimens diameter is flow value. Cantabro test that its principle is determination percentage of specimens mass losses, carried out on the compacted samples, after the fulfillment 300 gyrations of Los Angeles machine at speed 30-33 rpm, mass losses of specimens were calculated by subtracting the mass of specimens before and after test. Moreover, Properties of asphalt mixture were inspected by the analyzing of voids fill with bitumen (VFB), air voids (V) and bulk specific gravity (BSG). The analysis of tests result was performed by using RSA 
with statistical analysis software (SAS). Recycled aggregate $(25 \%, 50 \%, 75 \%$ and $100 \%)$ and two different types of binders $(50 / 70$ and $70 / 100)$ that formed the hot mixture were used as variables in the RSA, then experimental data were analyzed by RSA method. RSA estimation is expressed by a general quadratic model shown in Eq. (1):

$$
\begin{aligned}
& Y_{i}=\beta_{0}+\beta_{1} x_{1 i}+\beta_{2} x_{2 i}+\beta_{3} x_{1 i}^{2}+\beta_{4} x_{2 i}^{2} \\
& \quad+\beta_{5} x_{1 i} x_{2 i}+\varepsilon_{i}
\end{aligned}
$$

where, $Y_{i}$ is calculated parameters of Marshall samples (Marshall stability, void etc.), $x_{11}$ is is first statistically estimated model parameter; $x_{2 i}$ is statistically estimated model parameter; $\beta_{0}$ is the intercept; $\beta_{1}, \beta_{2}, \beta_{3}, \beta_{4}$, and $\beta_{5}$ are the interaction coefficients of linear, quadratic and second order terms, respectively; and $\varepsilon_{i}$ is the error term. The closeness of model fit in Eq. (1) has been accepted as the coefficient of determination $\left(\mathrm{R}^{2}\right)$.

\section{Results and discussion}

Results of RSA that estimate the properties (void, VFB, BSG) and performance (stability, flow, mass-loss) of mixtures which formed with 4 different RRA rates and two different types of binder are shown in Table I.

Response surface analysis results.

\begin{tabular}{|c|c|c|c|c|c|c|c|}
\hline Dependent & Parameter & DF & estimate & std err & $t$ value & probt & $\overline{R^{2}}$ \\
\hline \multirow{6}{*}{ Void } & Intercept & 1 & 8.268571 & 0.442156 & 18.70 & $<0.0001$ & 0.9839 \\
\hline & RRA & 1 & 0.002154 & 0.010327 & 0.21 & 0.8430 & \\
\hline & BITUMEN & 1 & -0.758000 & 0.273215 & -2.77 & 0.0392 & \\
\hline & $\mathrm{RRA}^{*} \mathrm{RRA}$ & 1 & -0.000105 & 0.000075414 & -1.39 & 0.2220 & \\
\hline & BITUMEN*RRA & 1 & -0.015360 & 0.004462 & -3.44 & 0.0184 & \\
\hline & BITUMEN*BITUMEN & 0 & 0 & - & - & - & \\
\hline \multirow{6}{*}{ VFB } & Intercept & 1 & 59.133000 & 4.277925 & 13.82 & $<0.0001$ & \\
\hline & RRA & 1 & -0.118600 & 0.099911 & -1.19 & 0.2885 & \\
\hline & BITUMEN & 1 & -1.214000 & 2.643391 & -0.46 & 0.6653 & \\
\hline & $\mathrm{RRA}^{*} \mathrm{RRA}$ & 1 & 0.000948 & 0.000730 & 1.30 & 0.2505 & \\
\hline & BITUMEN*RRA & 1 & 0.125720 & 0.043166 & 2.91 & 0.0333 & \\
\hline & BITUMEN*BITUMEN & 0 & 0 & - & - & - & \\
\hline \multirow{6}{*}{ Stability } & Intercept & 1 & 9.091429 & 0.722274 & 12.59 & $<0.0001$ & 0.9160 \\
\hline & RRA & 1 & -0.014234 & 0.016869 & -0.84 & 0.4373 & \\
\hline & BITUMEN & 1 & -0.362000 & 0.446304 & -0.81 & 0.4542 & \\
\hline & $\mathrm{RRA}^{*} \mathrm{RRA}$ & 1 & -0.000103 & 0.000123 & -0.83 & 0.4418 & \\
\hline & BITUMEN*RRA & 1 & -0.001040 & 0.007288 & -0.14 & 0.8921 & \\
\hline & BITUMEN*BITUMEN & 0 & 0 & - & - & - & \\
\hline \multirow{6}{*}{ B.S. Gravity } & Intercept & 1 & 2.318286 & 0.005686 & 407.74 & $<0.0001$ & 0.9938 \\
\hline & RRA & 1 & 0.000097143 & 0.000133 & 0.73 & 0.4973 & \\
\hline & BITUMEN & 1 & 0.022000 & 0.003513 & 6.26 & 0.0015 & \\
\hline & $\mathrm{RRA}^{*} \mathrm{RRA}$ & 1 & 0.000003429 & 0.000000970 & 3.54 & 0.0166 & \\
\hline & BITUMEN*RCA & 1 & 0.000160 & 0.000057371 & 2.79 & 0.0385 & \\
\hline & BITUMEN*BITUMEN & 0 & 0 & - & - & - & \\
\hline \multirow{6}{*}{ Marshall Flow } & Intercept & 1 & 2.772000 & 0.105835 & 26.19 & $<0.0001$ & 0.9957 \\
\hline & RRA & 1 & 0.014080 & 0.002472 & 5.70 & 0.0023 & \\
\hline & BITUMEN & 1 & 0.374000 & 0.065397 & 5.72 & 0.0023 & \\
\hline & RRA*RRA & 1 & 0.000056000 & 0.000018051 & 3.10 & 0.0268 & \\
\hline & BITUMEN*RRA & 1 & -0.001440 & 0.001068 & -1.35 & 0.2354 & \\
\hline & BITUMEN*BITUMEN & 0 & 0 & - & - & - & \\
\hline \multirow{6}{*}{ Mass-Loss } & Intercept & 1 & 40.375714 & 9.348971 & 4.32 & 0.0076 & 0.8192 \\
\hline & RRA & 1 & -0.664897 & 0.218345 & -3.05 & 0.0286 & \\
\hline & BITUMEN & 1 & -15.522000 & 5.776863 & -2.69 & 0.0435 & \\
\hline & RRA*RRA & 1 & 0.004677 & 0.001595 & 2.93 & 0.0325 & \\
\hline & BITUMEN*RRA & 1 & 0.087120 & 0.094336 & 0.92 & 0.3981 & \\
\hline & BITUMEN*BITUMEN & 0 & 0 & - & - & - & \\
\hline
\end{tabular}

TABLE I 
The $R^{2}$ values of response surface for recycled aggregates and bitumen type that used as variation shows the estimation properties and performance values of Marshall samples. As it seems in Table I, $R^{2}$ values are quite high. This shows that estimation models quite reliable in predicting Marshall sample's properties and performance especially in the Marshall flow and BSG values which obtained $99 \%$. The results obtained from RSA has indicated that the estimation models have high $\mathrm{R}^{2}$ values (higher than $81 \%$ ) which could be used for predicting properties and performance of samples. In addition, Fig. 1 shows the response surface charts of these analyzes.
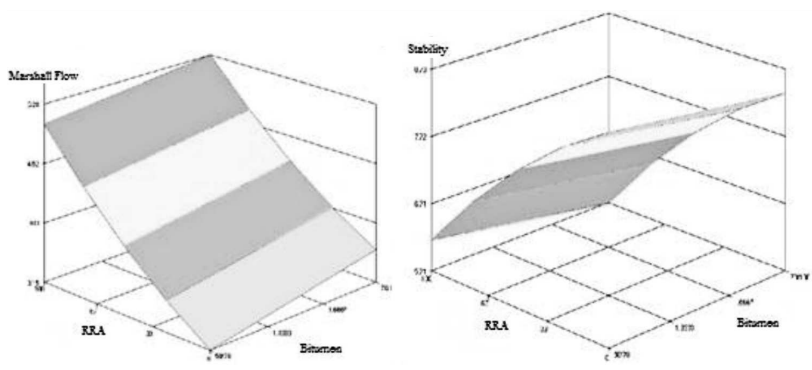

Fig. 1. Response surface charts.

\section{Conclusion}

Since the experimental studies are based on the parameters of high cost and long-term of work, these parameters increase with the increasing number of experiments. So, nowadays new methods that is being followed by investigators can evaluate input data easier and faster. In the method of RSA first, a certain number of experimental studies are carried out and then the possible experiment results are statistically estimated. Therefore, the suitability of the parameters which used to obtain the results of experimental studies is very important. In this study, successful prediction rate was obtained through RSA $\left(R^{2} \geq 81\right)$. On the basis of these results, the response surface analysis that obtained in this study in order to predict the asphalt mixture performance was considered reasonable. It concluded that RSA can be used as a numerical method for the prediction of asphalt mixture performance due to the high value of $R^{2}$.

\section{Acknowledgments}

This research was sponsored by the BAP (Scientific Research Projects Coordination Unit of Akdeniz University, Turkey) with the project code: FYL-2017-2360

\section{References}

[1] G.E.P. Box, N.R. Draper, Empirical Model Building and Response Surfaces, Wiley, New York 1987.

[2] B. Golchin, A. Mansourian, Int. J. of Transportation Engineerig 4, 335 (2017).

[3] M.O. Hamzah, B. Golchin, C. Thian, Construction and Building Materials 47, 1328 (2013).

[4] G. Saha, K.P. Biligiri, Materials and Structures 5033 (2017).

[5] A. Hamrouni, D. Dias, B. Sbartai, Underground Space 2, 246 (2017).

[6] H. Guimaraes, J.C. Matos, A.A. Henriques, Structural Safety 73, 12 (2018).

[7] M.O. Hamzah, L. Gungat, B. Golchin, Int. J. of Pavement Engineering 18, 682 (2017).

[8] C. Lu, Y. Feng, R.P. Liem, C. Fei, Aerospace Science and Technology 76, 164 (2018).

[9] J. Zhang, H.Z. Chen, H.W. Huang, Z. Luo, Computers and Geotechnics 69, 496 (2015).

[10] G. Zheng, H. Nie, M. Luo, J. Chen, J. Man, C.Chen, H.P. Lee, Acta Astronautica 148, 225 (2018). 